In brief

\title{
Work Programme Consultation
}

The Office for National Statistics (ONS) is seeking views to help determine the shape of its future statistical work programme. The budget reductions announced as part of the 2010 Spending Review mean that ONS has to consider where savings can be found. It is critically important that our statistical outputs reflect our users' priorities. User feedback can also help us strive to become a more efficient and effective organisation.

The consultation document outlines our approach to reducing our budget, including the core principles which determine this approach, and asks stakeholders to let us know:

- what ONS outputs they use and how they use them

- the impact on them of possible reductions in various areas of ONS work.

Responses will be used to inform our work programme for the next four years.

Population Trends readers may access the required template (in both pdf and Word formats) at: www.ons.gov.uk/about/consultations/work-programme-consultation/index.html

Responses, using the template provided, should be sent to:

Email: stakeholderconsultation@ons.gsi.gov.uk

Work Programme Consultation

Room 1301

Office for National Statistics

Government Buildings

Cardiff Road

Newport

\section{Progress on the 2011 Census}

\section{Comprehensive spending review}

In October 2011, the government's Comprehensive Spending Review (CSR) confirmed the 2011 Census budget for 2011/12 (which fully covers the operational period of the census - including, for example, field staff, processing of questionnaires etc) was in place and not subject to alteration.

Further to this, for the CSR periods of 2012/13 and 2014/15, the 2011 Census programme has been allocated the required funds to complete the census. 


\section{Recruitment}

Recruitment for 35,000 census collectors began in October 2010, with a good response across England and Wales. The recruitment, pay and training contract is outsourced to Capita who are managing the full process including training (classroom and e-learning) in the months prior to the census.

Census coordinators - looking after teams of collectors - will shortly join the area managers (responsible for engaging their local geographic communities and managing the field force once operational) and community advisors (who are responsible for increasing census awareness and encouraging participation within ethnic communities including Somali, Pakistani, Bangladeshi and others).

\section{Address check}

The majority of the census field staff will be deployed to collect questionnaires from households who have not returned them, using a comprehensive address register and questionnaire tracking system. Two national address lists, including the National Land and Property Gazetteer and Royal Mail's Postcode Address File were merged to create the census address register and a field check took place during the summer 2010.

Address checkers were sent out to look at the validity of the register and investigate any remaining mismatches between the two data sets. 15 per cent of England and Wales's postcodes were identified as more likely to have challenges for the register and these were therefore checked with successful results.

The quality of the address checking itself was tested, by suppressing a random element of the list, and tracking the rates of discovery by the address checkers, again a successful outcome.

The overall process confirmed the quality of the sources of evidence and addresses from local authorities and data suppliers and showed that the address register is on target to include more than 99 per cent of households come 2011.

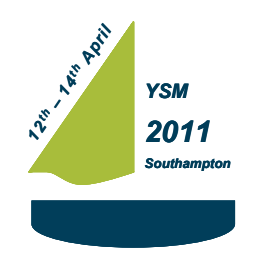

\section{Young Statisticians' Meeting 2011}

On 12-14 April 2011 the Young Statisticians' Meeting (YSM) will be held at the University of Southampton. This is a two and a half day conference that brings together young statisticians - those in the first ten years of their statistical career - from across government, industry and academia.

Registration for this event is now open and delegates are invited to submit abstracts for oral and poster presentations for a number of parallel sessions and a poster presentation session. The YSM 2011 also provides delegates with an excellent opportunity to experience a variety of statistical topics currently being researched and to explore the debates around wider issues in statistics. Registration can be accessed at: http://sites.google.com/site/ysm2011conference/registration

This year, the conference will focus on the debate around the extent to which personal data should be held by the Government. There will be a special 'Dinner and Debate' session on the first day of 
the conference where three guest speakers - including David Bond, a freelance journalist known for his reporting on the use of personal data - will sit on a panel to discuss their opinions on this topic and answer delegate's questions.

In addition, there will be workshops on the Census and Data Visualisation. The Census workshop will feature Owen Abbott from Census Methodology speaking about the statistical challenges of the 2011 Census and Roeland Beerton from Beyond 2011 exploring possible alternatives to future censuses.

For full details about the YSM 2011 please visit:

http://sites.google.com/site/ysm2011conference/home

\section{Fertility and mortality in England and Wales: new interactive mapping tool}

Fertility and mortality in England and Wales is an interactive mapping tool which allows you to analyse total fertility rates for females and age-standardised mortality rates for males and females at the local authority level more easily.

Animating the map allows you to see how fertility and mortality rates have changed over time for each area. The mapping tool can be found at: www.statistics.gov.uk/births-deaths/default.htm

Fertility and mortality in England and Wales was released alongside mortality statistics 2009 (26 October 2010).

\section{Population estimates for Scotland's Centenarians, 2002-2009}

On 30 September 2010 the General Register Office for Scotland published its population estimates of centenarians for Scotland, giving yearly figures from mid-2002 to mid-2009. The key points are:

- Centenarians are the most rapidly growing age-group of Scotland's population

- The estimates for 2009 show that elderly women greatly outnumbered elderly men. Women made up 75 per cent of the 90-99 age group and 85 per cent of the centenarians

- The number of centenarians in Scotland from 2002 to 2009 has increased from 570 in 2002 to 750 in 2009, a rise of 32 per cent

- Although there are many more female than male centenarians, the number of male centenarians is increasing more rapidly. Over the last 7 years the number of women aged 100 or more has increased by about a quarter whereas the number of men aged 100 or more has increased by two thirds

- Centenarians are still rare. However the number of centenarians in the total population has increased from 1.1 per 10,000 in 2002 to 1.4 per 10,000 in 2009. Male centenarians showed the strongest rise relative to the total population. Increasing from 0.25 per 10,000 to 0.40 per 10,000

- Centenarians make up a slightly larger proportion in the whole of the UK than in Scotland, and the rate of increase in the number in the whole of the UK is greater than in Scotland for both men and women.

Further details of population statistics for Scotland:

www.gro-scotland.gov.uk/statistics/theme/population/index.html 


\section{Life Expectancy for Administrative areas within Scotland, 2007-2009}

On 16 September 2010 the General Register Office for Scotland published its life expectancy estimates for administrative areas within Scotland based on the years 2007-2009. The key points are:

At birth:

- Life expectancy was 75.4 years for men and 80.1 years for women

- There were considerable variations in life expectancy across Scotland

- The Council area with the highest life expectancy for men (78.3 years) and women (83.1 years) was East Dunbartonshire. This was 7.2 years more for men and 5.6 years more for women than Glasgow City, which had the lowest life expectancy for men (71.1 years) and women (77.5 years)

- For men, the NHS Board area with the highest life expectancy was Borders (77.1 years), with the life expectancy of women being highest in Western Isles (82.0 years). The NHS Board area with the lowest life expectancy for men and women was Greater Glasgow \& Clyde (73.1 years and 78.9 years respectively).

At age 65:

- Men could expect to live for a further 16.5 years and women a further 19.1 years

- The Council area with the highest life expectancy at age 65 for men (18.3 years) and women (20.9 years) was East Dunbartonshire, 4.4 years more for men and 3.3 years more for women than Glasgow City, which had the lowest life expectancy at age 65 for men and women

- The NHS Board area with the highest life expectancy at age 65 for men and women was Shetland (18.0 years and 20.7 years respectively). The lowest life expectancy at age 65 for men was in Greater Glasgow \& Clyde (15.2 years) and for women was in Lanarkshire (18.3 years).

Compared with 10 years ago in 1997-1999:

- Life expectancy at birth in Scotland has increased by 2.7 years for men (from 72.7 years to 75.4 years) and by 1.9 years for women (from 78.2 years to 80.1 years)

- The gap between male and female life expectancy continues to close, dropping from 5.5 years in 1997-1999 to 4.8 years in 2007-2009

- The life expectancy did not decrease in any Council or NHS Board area over the 10 year period, although increase in life expectancy was as low as 1.6 per cent

- For men, the gap between the highest and lowest life expectancy in Council areas deceased by 0.6 years - from 7.8 years to 7.2 years over the 10 year period. For women, the gap increased by 0.4 years - from 5.2 years to 5.6 years.

Compared with the UK and Europe:

- Scottish men and women have among the lowest life expectancy at birth in the EU27 countries and their life expectancy is slightly less than the EU27 average (1.0 years for men and 2.3 years for women)

- Making comparison with the EU27 countries which have the highest life expectancies, Scottish men can expect to live 4.0 years less than Swedish men and Scottish women can expect to live 4.9 years less than French women 
- Based on 2007 figures, life expectancy at birth within the UK is 2.5 years higher for men than in Scotland and 1.8 years higher for women (ONS figures available at: www.statistics.gov.uk/StatBase/Product.asp?vlnk=8841 )

- Scotland's position relative to the UK and EU27 average figures is not improving and has worsened over the past 5 years.

Further details at:www.gro-scotland.gov.uk/statistics/publications-and-data/life-expectancy/leadmin-areas07-09/index.html

\section{Wales's Population 2010}

The fourth comprehensive overview of demographic statistics for Wales (Wales's Population 2010) was published on the 27th October 2010.

The report brings together information on the demography of Wales for the period 1971 to 2009 . It looks at population and migration estimates, birth and death patterns, and also focuses on the 2008-based national population projections, and the recently published 2008-based local authority projections for Wales.

Wales' population in 2009 stood at just under 3 million and is projected to reach 3 million between mid-2009 and mid-2010. The population of Wales is projected to increase by 8 per cent from 2008 to 3.2 million in 2023.

This Publication and further information on population in Wales is available on the Welsh Assembly website: www.wales.gov.uk/topics/statistics/theme/population/?lang=en

\section{Baby names comparison tool}

The baby names comparison tool is an interactive tool which allows you to analyse changing trends in boys and girls names in England and Wales. The tool enables comparison of baby name rankings in 2009, 2008 and 1999.

The tool can be found at: www.statistics.gov.uk/babynames/default.htm

The baby names comparison tool was released on 27 October 2010 with the release of 2009 baby name statistics. 